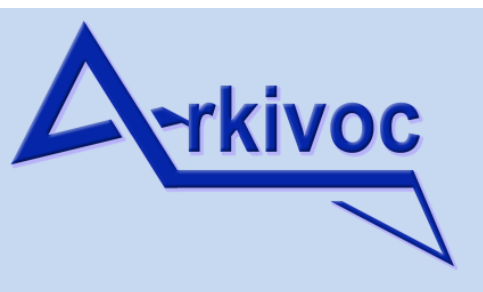

Archive for

Organic Chemistry
The Free Internet Journal

for Organic Chemistry
Paper

Arkivoc 2018, part iii, 90-101

\title{
Gold catalyzed synthesis of tetrahydropyrimidines and octahydroquinazolines under ball milling conditions and evaluation of anticonvulsant potency
}

\author{
M. Vadivelu, ${ }^{a}$ A. A. Raheem, ${ }^{\text {b }}$ S. Sugirdha, ${ }^{a}$ G. Bhaskar, ${ }^{c}$ K. Karthikeyan, ${ }^{* a}$ and C. Praveen ${ }^{* b}$
}

${ }^{a}$ Department of Chemistry, B. S. Abdur Rahman Crescent University, Chennai-600 048, Tamil Nadu, India ${ }^{b}$ Functional Materials Division, Central Electrochemical Research Institute (CSIR Laboratory), Karaikudi-630003,

Tamil Nadu, India

'Department of Chemistry, Government Polytechnic College, Aranthangi-614 616, Tamil Nadu, India

Email: karthiclri@gmail.com; chandrasekar.praveen@gmail.com

Dedicated with respect to Dr. P. T. Perumal for his 35 years of contribution to synthetic organic chemistry

Received 10-23-2017

Accepted 12-16-2017

Published on line 12-21-2017

\section{Abstract}

A fast, mechanochemical and solvent-free synthesis of substituted tetrahydropyrimidines and octahydroquinazolines under Au(III)-catalysis has been developed. The practical feasibility, eco-friendliness and operational simplicity of this chemistry is exemplified by ball milling three components such as formaldehyde, amines and 2-butynedioates/dimedone in a shaker mill for as little as five minutes, thus avoiding the requirement of undesirable solvents and long reaction times. Moreover, this protocol furnishes the target compounds in high yields without any side products and in some cases offers products with excellent regioselectivity. Out of the 26 compounds screened for anticonvulsant potency, 11 compounds exhibited comparable activity against a standard drug.

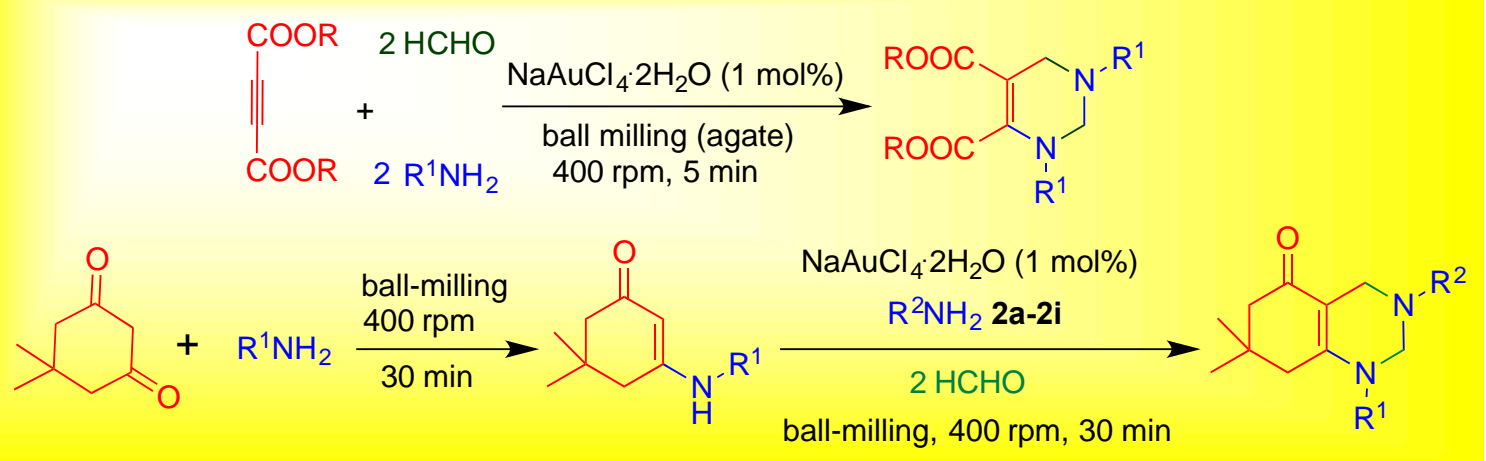

Keywords: Mechanochemistry, gold catalysis, multicomponent reaction, tetrahydropyrimidines, octahydroquinazolines, anticonvulsant 


\section{Introduction}

Green chemistry has become one of the powerful tools for organic chemists to increase molecular complexity from simple substrates in a convenient manner. ${ }^{1}$ In particular, circumvention of solvents in chemical processes or the replacement of hazardous organic solvents with environmentally benign solvents has received paramount importance in the context of a green economy. Within the purview of sustainable development, the current areas of interest are to synthesize complex molecular frameworks by multicomponent reactions, ${ }^{2}$ solvent-free organic transformations, ${ }^{3}$ and water-assisted organic reactions. ${ }^{4}$ Especially, multicomponent reactions under one-pot conditions have substantial advantage over multistep synthesis, because of i) the construction of complex molecules from readily available raw materials, ii) operational simplicity, iii) reduction of intermediate isolation as well as purification steps and iv) minimization of cost/time/waste. ${ }^{5}$

Pyrimidines and their analogues represent an important class of nitrogen heterocycles which are found as key structural constituent in various bio-active natural compounds and clinical drugs. ${ }^{6-8}$ Specifically, tetrahydropyrimidines have attracted much attention, because of their interesting and unique therapeutic properties such as muscarinic agonist activity, ${ }^{9}$ anti-inflammatory activity, ${ }^{10}$ and antiviral activity. ${ }^{11}$ It is also noteworthy are the magnetic properties of pyrimidinyl nitronyl nitroxide radicals. ${ }^{12}$ However, the reported methodologies have not been entirely satisfactory because of the associated drawbacks such as low yields, long reaction time and cumbersome experimental processes. ${ }^{13}$ Some of the previous multicomponent syntheses of tetrahydropyrimidines involve $\mathrm{ZrOCl}_{2}$ catalysis in water, ${ }^{14}$ refluxing in $\mathrm{DMF},{ }^{15}$ and iodine catalysis under reflux. ${ }^{16}$ Though these strategies are synthetically attractive, their utility is limited only to the synthesis of tetrahydropyrimidines and no octahydroquinazoline syntheses were demonstrated. As part of our research interests on new synthetic methodologies for pharmacologically important molecules, ${ }^{17-32}$ we have demonstrated the catalytic application of gold for the construction of various structurally challenging carboand heterocycles. ${ }^{33-48}$ In order to circumvent the aforementioned limitations linked with the synthesis of dihydropyrimidines, coupled with our research interests in gold catalysis, we have now investigated the synthesis of both tetrahydropyrimidines and octahydroquinazolines under the catalytic influence of gold. Towards this end, we herein report an improved methodology for the solvent-free synthesis of tetrahydrohydropyrimidine / octahydroquinazoline derivatives under mechanochemical conditions in presence of $\mathrm{Au}(\mathrm{III})$ as catalyst.

\section{Results and Discussion}

\section{Synthesis of tetrahydropyrimidine derivatives}

Based on our previous experience with $\mathrm{NaAuCl}_{4} \cdot 2 \mathrm{H}_{2} \mathrm{O},{ }^{34}$ which can serve as both an oxophilic as well as a carbophilic catalyst, we initiated our studies using this particular catalyst. We aimed at solvent-free conditions, however, in order to drive the reaction between the substrates, the reactants have to be close enough, which we thought could be achieved by mechanical chemistry. ${ }^{49}$ In this connection, we initially evaluated the reaction between a mixture of diethyl but-2-ynedioate $1 \mathrm{a}(1.0 \mathrm{mmoL})$, aniline $2 \mathrm{a}(2.0 \mathrm{mmoL})$, formaldehyde $(2.0 \mathrm{mmoL})$ and $\mathrm{NaAuCl}_{4} \cdot 2 \mathrm{H}_{2} \mathrm{O}(1 \mathrm{~mol} \%)$ ball-milled at $400 \mathrm{rpm}$ for 5 minutes (Scheme 1$)$. 


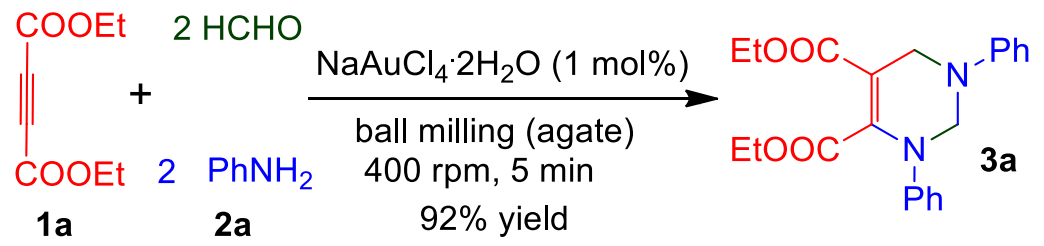

Scheme 1. Prototype reaction under ball-milling.

We were pleased to find that the reaction proceeds smoothly under this conditions and the starting materials were consumed completely as evidenced by TLC. Purification of the crude residue by column chromatography afforded the product $\mathbf{3 a}$ in excellent yield (92\%). The structure of the isolated product $\mathbf{3 a}$ was assigned based on IR, NMR and mass spectral data. The IR spectrum of 3a exhibits a strong stretching peak at $1740 \mathrm{~cm}^{-1}$ corresponding to ester groups. In the ${ }^{1} \mathrm{H}$ NMR spectrum of $3 \mathrm{a}$, two triplets at $\delta 0.98(\mathrm{t}, J 6.8 \mathrm{~Hz}, 3 \mathrm{H})$, $1.27(\mathrm{t}, J 6.8 \mathrm{~Hz}, 3 \mathrm{H})$ and two quartets at $\delta 4.02(\mathrm{q}, J 6.8 \mathrm{~Hz}, 2 \mathrm{H}), 4.18(\mathrm{q}, J 6.8 \mathrm{~Hz}, 2 \mathrm{H})$ were assigned to $\mathrm{CH}_{3^{-}}$ and $\mathrm{CH}_{2}$ - of the two ester groups respectively. The two singlets at $\delta 4.26(\mathrm{~s}, 2 \mathrm{H}), 4.90(\mathrm{~s}, 2 \mathrm{H})$ were attributed to the two $\mathrm{CH}_{2}$ - groups in the tetrahydropyrimidine ring. In the ${ }^{13} \mathrm{C} N M R$ spectrum, the peaks at $\delta 164.0$ and $165.7 \mathrm{ppm}$ were assigned to the two carbonyl groups. Finally the structure was confirmed by mass spectrometry, which showed an ion at $m / z=381$ corresponding to $[\mathrm{M}+1]^{+}$. Delighted with the initial positive result, we next assessed the role of catalyst in this reaction. In a blank reaction without using $\mathrm{NaAuCl}_{4} \cdot 2 \mathrm{H}_{2} \mathrm{O}$ and even after one hour, only a minimal quantity of starting materials was consumed, thus supporting the catalytic role of $\mathrm{NaAuCl}_{4} \cdot 2 \mathrm{H}_{2} \mathrm{O}$ in this transformation. Satisfied with the initial excellent result, we chose these conditions, which are practical to perform and also environmentally friendly, for the synthesis of structurally different tetrahydropyrimidines. When these reaction conditions were applied to other substrates, the desired products 3a-g were obtained in good to excellent chemical yields (Scheme 2). Significantly, our chemistry is tolerant towards aliphatic, benzylic and aromatic amines. However, we used only formaldehyde for our reactions because of its high reactivity and because attempted use of other aldehydes possessing alkyl or aryl groups, afforded complex products. All reactions went to completion within five minutes and the results are summarized in Table 1.

Table 1 Tetrahydropyrimidines 3a-g prepared under ball-milling conditions

\begin{tabular}{|c|c|c|c|c|}
\hline Entry & $\mathrm{R}(\mathbf{1})$ & $\mathrm{R}^{1}(2)$ & Product $(3)^{a}$ & Yield $(\%)^{b}$ \\
\hline 1 & Et (1a) & $\mathrm{Ph}(2 \mathrm{a})$ & $3 a$ & 92 \\
\hline 2 & Et (1a) & $B n(2 b)$ & $3 b$ & 95 \\
\hline 3 & Me (1b) & $t-\mathrm{Bu}(2 \mathrm{c})$ & $3 c$ & 87 \\
\hline 4 & Me (1b) & $B n(2 b)$ & $3 d$ & 90 \\
\hline 5 & Et (1a) & $o-\mathrm{ClC}_{6} \mathrm{H}_{4}(2 \mathrm{~d})$ & $3 e$ & 85 \\
\hline 6 & Me (1b) & $p-\mathrm{BrC}_{6} \mathrm{H}_{4}(2 \mathrm{e})$ & $3 f$ & 93 \\
\hline 7 & Et (1a) & $t-\mathrm{Bu}(2 \mathrm{c})$ & $3 g$ & 85 \\
\hline
\end{tabular}

aproducts were characterized by $\mathrm{IR},{ }^{1} \mathrm{H} N M R,{ }^{13} \mathrm{C} N M R$ and mass spectrometry

bIsolated yield of products after column chromatography 


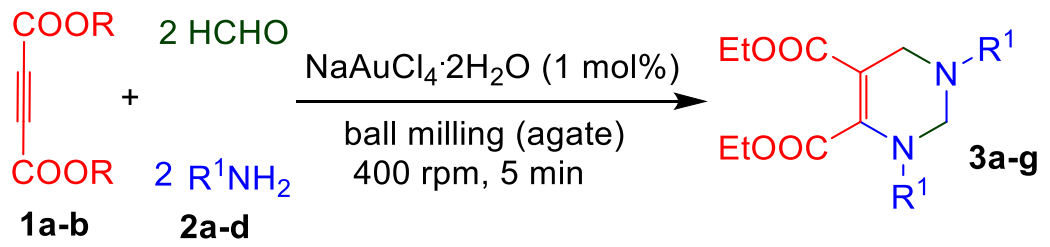

Scheme 2. Synthesis of 1,3-symmetrically substituted tetrahydropyrimidines.

In an attempt to glean information about the regiochemistry of our methodology, unsymmetrical alkynes such as $\mathbf{1} \mathbf{c}$ and $\mathbf{1 d}$ were subjected to the standardized conditions (Scheme 3). According with our expectations, only products $\mathbf{3} \mathbf{h}$ and $\mathbf{3} \mathbf{i}$ were obtained, whilst the corresponding regioisomers $\mathbf{3} \mathbf{h}^{\prime}$ and $\mathbf{3} \mathbf{i}^{\prime}$ were not obtained. This can be attributed to the partial depletion of electron density at the $\beta$-carbon by COOEt group, which directs the attack of nucleophilic amine towards the $\beta$-carbon of gold-activated alkyne I selectively to form the enaminium intermediate II for further transformation.

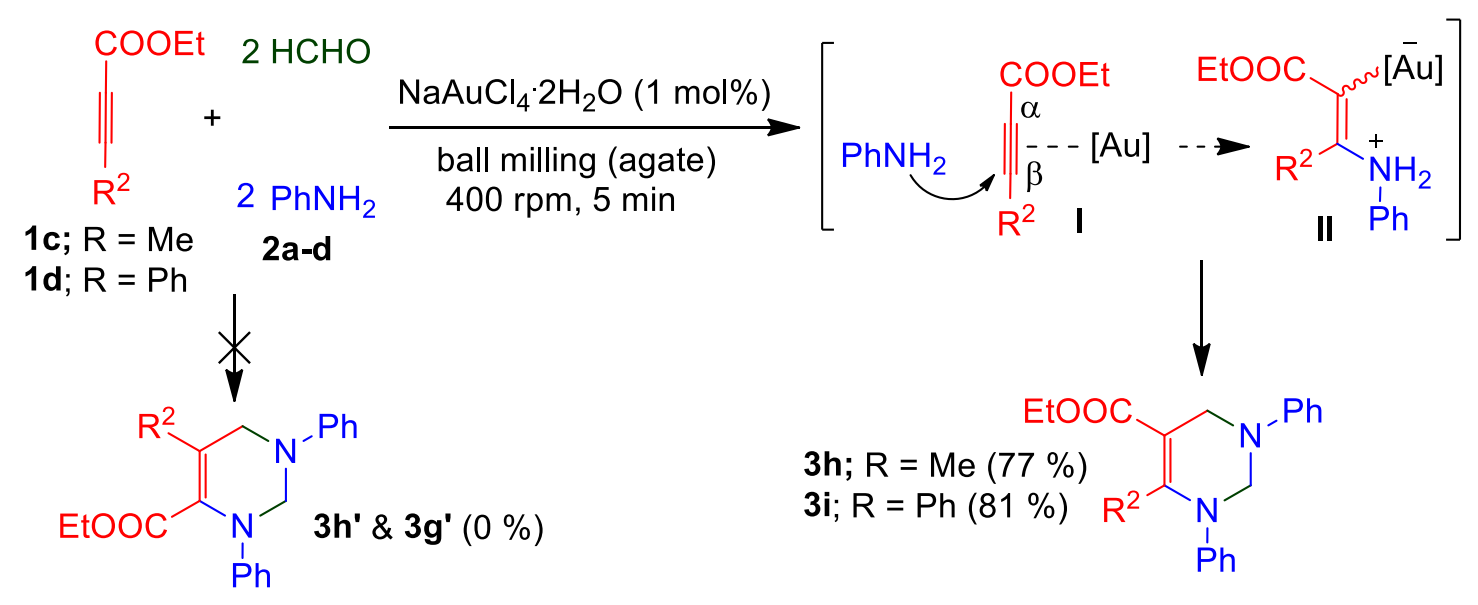

Scheme 3. Regioselective synthesis of tetrahydropyrimidines from unsymmetrical alkynes.

Having established a satisfactory protocol for the synthesis of 1,3-symmetrically substituted tetrahydropyrimidines, we next directed our studies towards the synthesis of 1,3-unsymmetrically substituted tetrahydropyrimidines using our reaction conditions. Towards this end, when we used differently substituted amines such as aniline and benzylamine at the same time, obtaining a mixture of two regioisomeric products as evidenced by NMR analysis of the crude product. In order to obtain a particular single product exclusively, we added the specified amines in a sequential manner. Thus, from the sequential addition of aniline $2 \mathbf{2 a}$ (amine 1) with $\mathbf{1 a}$, followed by addition with benzylamine $\mathbf{2} \mathbf{b}$ (amine 2), we obtained the desired product $\mathbf{5 a}$ as the sole product (Scheme 4). We believe that 2a initially undergoes typical gold-activated hydroamination with 1 a to form intermediate $\mathbf{4}$, which then subsequently reacts with $\mathbf{2} \mathbf{b}$ and formaldehyde to generate the product $5 a$. 


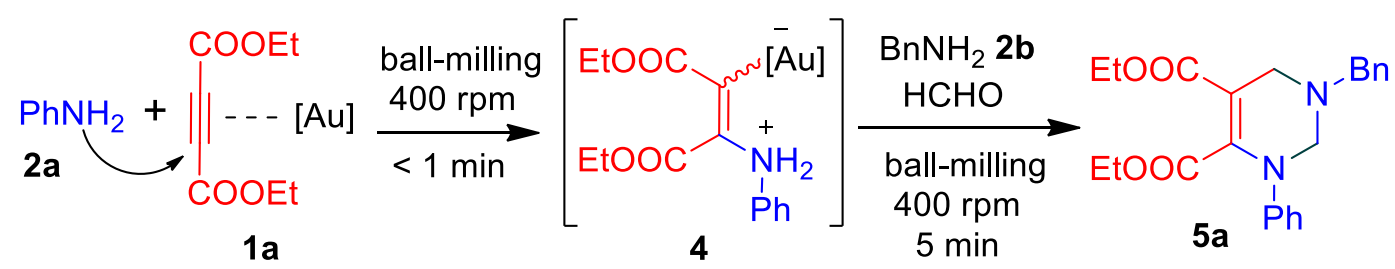

Scheme 4. Rationale for the formation of tetrahydropyrimidine 5a from two different amines.

The structure of the product was assigned based on NMR and mass spectral data. In the ${ }^{1} \mathrm{H}$ NMR spectrum of compound 5a, the two triplets at $\delta 1.02(\mathrm{t}, J 6.9 \mathrm{~Hz}, 3 \mathrm{H}), 1.22(\mathrm{t}, J 7.6 \mathrm{~Hz}, 3 \mathrm{H})$ and two quartets at $\delta 4.05(\mathrm{q}, J$ $6.9 \mathrm{~Hz}, 2 \mathrm{H}), 4.13(\mathrm{q}, J 7.6 \mathrm{~Hz}, 2 \mathrm{H})$ was assigned to $-\mathrm{CH}_{3}$ and $-\mathrm{CH}_{2}$ of two ester groups respectively. The three singlets at $\delta 3.71(\mathrm{~s}, 2 \mathrm{H}), 3.81(\mathrm{~s}, 2 \mathrm{H})$ and $4.33(\mathrm{~s} 2 \mathrm{H})$ were attributed to two $-\mathrm{CH}_{2}$ groups in the pyrimidine ring and one benzylic $-\mathrm{CH}_{2}$ group. In the ${ }^{13} \mathrm{C}$ NMR spectrum, the peaks at $\delta 164.2$ and 166.3 ppm were assigned to the two ester carbonyl carbons. Finally, the structure of the compound was unequivocally confirmed by a mass spectrum which showed $m / z=395(M+1)^{+}$. Pleased with these results, we incorporated differently substituted amines in a sequential manner for the synthesis of a range of 1,3-unsymmetrical tetrahydropyrimidines (Scheme 5). As depicted in Table 2, the sequences afforded good to excellent yields of products in about five minutes tolerating both alkyl and aromatic amines. However, the yields of the products was slightly diminished for ortho-substituted and bulky amines (entries 4 and 5), perhaps due to a steric effect.

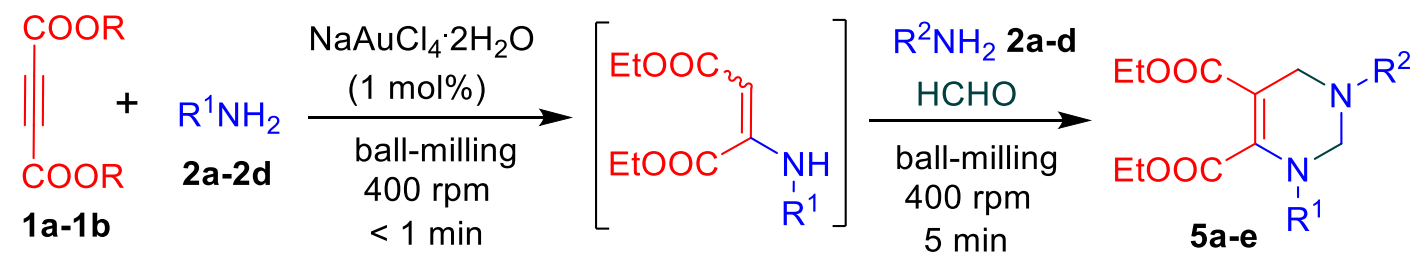

Scheme 5. Synthesis of 1,3-unsymmetrically substituted tetrahydropyrimidines .

Table 2 Tetrahydropyrimidines 5a-e prepared under ball-milling conditions

\begin{tabular}{ccccc}
\hline Entry & $\mathrm{R}^{1}(\mathbf{2})$ & $\mathrm{R}^{2}(\mathbf{2})$ & $\begin{array}{c}\text { Product } \\
(\mathbf{5})^{\mathrm{a}}\end{array}$ & Yield (\%) \\
\hline 1 & $\mathrm{Ph}(\mathbf{2 a})$ & $\mathrm{Bn}(\mathbf{2 b})$ & $\mathbf{5 a}$ & 91 \\
2 & $\mathrm{Bn} \mathrm{(2b)}$ & $\mathrm{Ph}(\mathbf{2 a})$ & $\mathbf{5 b}$ & 94 \\
3 & $\mathrm{Ph}(\mathbf{2 a})$ & $t-\mathrm{Bu}(\mathbf{2 c})$ & $\mathbf{5 c}$ & 92 \\
4 & $\mathrm{Ph}(\mathbf{2 a})$ & $o-\mathrm{Cl}-\mathrm{C}_{6} \mathrm{H}_{4}(\mathbf{2} \mathbf{d})$ & $\mathbf{5 d}$ & 76 \\
5 & $o-\mathrm{ClC}_{6} \mathrm{H}_{4}(\mathbf{2 d})$ & $\mathrm{Ph}(\mathbf{2 a})$ & $\mathbf{5 e}$ & 79 \\
\hline
\end{tabular}

aProducts were characterized by $\mathrm{IR},{ }^{1} \mathrm{H} N \mathrm{NMR},{ }^{13} \mathrm{C}$ NMR and mass spectrometry

bIsolated yields of products after column chromatography

\section{Synthesis of octahydroquinazoline derivatives}

Up to this point, we have described the reactivity of acetylenic precursors (1a-1d) for the synthesis of tetrahydropyrimidines. A further extension of this methodology was envisaged in the one-pot synthesis of octahydroquinazoline derivatives under our reaction conditions. Such compounds are little known in 
literature, hence their biological properties remain largely unexplored. We began with a control experiment treating dimedone $6(1.0 \mathrm{mmoL})$ with aniline $2 \mathrm{a}(1.0 \mathrm{mmoL})$ to form the enaminone intermediate 7 under ballmilling for 30 minutes without added catalyst (Scheme 6). To this enaminone intermediate was added another mole of aniline and formaldehyde $(2.0 \mathrm{mmoL})$ in presence of $\mathrm{NaAuCl}_{4} \cdot 2 \mathrm{H}_{2} \mathrm{O}$ (1 mol\%) and ball-milling continued for the next 30 minutes. To our delight, the targeted product 1,2,3,4,7,8-hexahydro-7,7-dimethyl1,3-diphenylquinazolin-5(6H)-one 8 a was isolated in $90 \%$ yield. However, the second transformation was not effected in the absence of the gold catalyst. These findings revealed that the catalytic action of $\mathrm{NaAuCl}_{4} \cdot 2 \mathrm{H}_{2} \mathrm{O}$ is required only for the second step and not for enaminone formation. Alternatively, the same reaction was carried out in a one-flask operation without isolating the enaminone by the addition of aniline (2.0 equiv) and formaldehyde (2.0 equiv) leading to the product $8 \mathrm{a}$ with almost the same yield (91\%). The structure of the compound 8a was assigned based on the NMR and mass spectral data. In the ${ }^{1} \mathrm{H}$ NMR spectrum, a sharp singlet at $\delta 0.93(6 \mathrm{H}, \mathrm{s})$ corresponds to the two methyl groups on the carbocyclic ring and two singlets at $\delta$ $2.00(2 \mathrm{H}, \mathrm{s})$ and $2.22(2 \mathrm{H}, \mathrm{s})$ correspond to the ring methylene groups. The methylene group protons adjacent to the nitrogen were represented by two singlets at $\delta 4.31(2 \mathrm{H}, \mathrm{s})$ and $4.94(2 \mathrm{H}, \mathrm{s})$. The ${ }^{13} \mathrm{C}$ NMR shows a peak at $\delta 28.4$ for two methyl carbons and a less intense peak at $\delta 32.7$ represents the quaternary carbon carrying two methyl groups. The peaks at $\delta 41.1$ and 50.1 corresponds to two methylene carbons of the carbocycle. The peaks at $\delta 45.6$ and 70.2 corresponds to the two methylene carbons in the pyrimidine ring. The double bond carbons shows two signals one at $\delta 104.9$ and another in the aromatic region. The carbonyl carbon signal was at $\delta$ 194.2. Finally the structural characterization was conclusively assigned by mass spectrometry, which showed $m / z=333[\mathrm{M}+1]^{+}$.

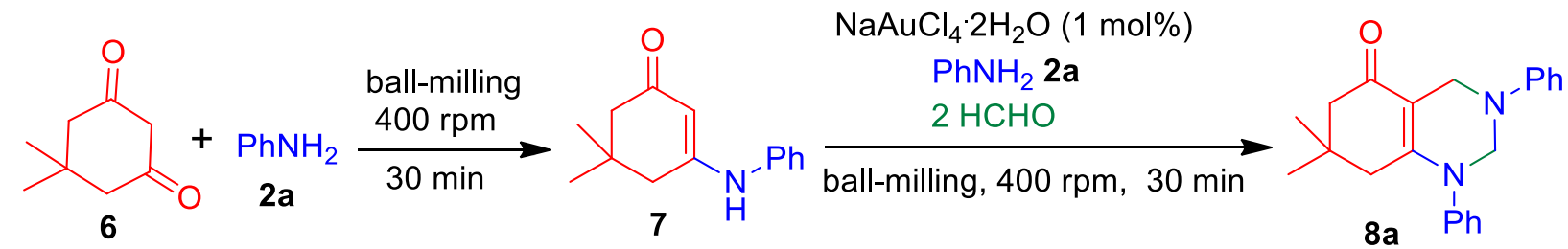

Scheme 6. Synthesis of 5-oxo-octahydroquinazoline 8a through two steps.

By utilizing our reaction conditions, both 1,3-symmetrical and 1,3-unsymmetrical 5-oxooctahydroquinazolines could be produced from a variety of amines and dimedone (Scheme 7). Analysis of the results as depicted in Table 3 reveals that there is an obvious steric effect of substituents on the reactivity as evidenced by reduced yields in case of substrates possessing ortho substitution (entries 4 to 7). Another distinguishing feature is the overall reaction time of one hour which is higher than for the synthesis of the tetrahydropyrimidines (compare Tables $1 \& 2$ with Table 3). We also examined the same transformation under conventional heating and compared with our mechanochemical process. Under neat conditions at $80{ }^{\circ} \mathrm{C}$ the yields of products from all substrates were found to be slightly lower than by the mechanochemical method, vindicating the effectiveness of the mechanochemical method over conventional heating for these transformations. 


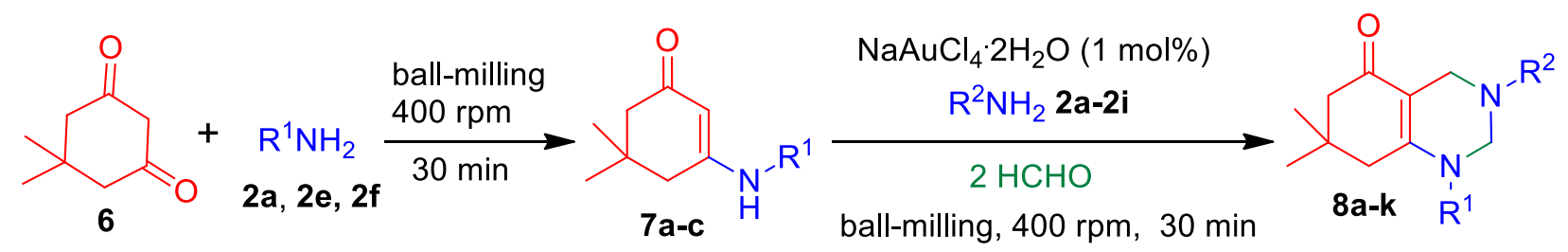

Scheme 7. Synthesis of 5-oxo-octahydroquinazoline derivatives 8a-k.

Table 3. 5-Oxo-octahydroquinazolines 8a-k prepared under ball-milling conditions

\begin{tabular}{|c|c|c|c|c|c|}
\hline Entry & $R^{1}(2)$ & $R^{2}(2)$ & $\begin{array}{c}\text { Product } \\
(\mathbf{8})^{\mathrm{a}}\end{array}$ & Yield $(\%)^{b, c}$ & Yield $(\%)^{b, d}$ \\
\hline 1 & $\mathrm{Ph}(2 \mathrm{a})$ & $\mathrm{Ph}(2 \mathrm{a})$ & $8 a$ & 91 & 75 \\
\hline 2 & $\mathrm{Ph}(2 \mathrm{a})$ & $p-\mathrm{BrC}_{6} \mathrm{H}_{4}(2 \mathrm{e})$ & $8 b$ & 85 & 68 \\
\hline 3 & $\mathrm{Ph}(2 \mathrm{a})$ & $p-\mathrm{MeOC}_{6} \mathrm{H}_{4}(\mathbf{2 f})$ & $8 c$ & 88 & 69 \\
\hline 4 & $\mathrm{Ph}(2 \mathrm{a})$ & $o, p-\mathrm{Me}_{2} \mathrm{C}_{6} \mathrm{H}_{3}(2 \mathrm{~g})$ & $8 d$ & 74 & 56 \\
\hline 5 & $\mathrm{Ph}(2 \mathrm{a})$ & $o-\mathrm{MeOC}_{6} \mathrm{H}_{4}(2 \mathrm{~h})$ & $8 e$ & 73 & 49 \\
\hline 6 & $\mathrm{Ph}(2 \mathrm{a})$ & $o-\mathrm{ClC}_{6} \mathrm{H}_{4}(2 \mathrm{~d})$ & $8 f$ & 75 & 44 \\
\hline 7 & $\mathrm{Ph}(2 \mathrm{a})$ & $o, p-\mathrm{Cl}_{2} \mathrm{C}_{6} \mathrm{H}_{3}(2 \mathrm{~g})$ & $8 g$ & 72 & 45 \\
\hline 8 & $\mathrm{Ph}(2 \mathrm{a})$ & $B n(2 b)$ & $8 h$ & 87 & 66 \\
\hline 9 & $\mathrm{Ph}(2 \mathrm{a})$ & $t-\mathrm{Bu}(2 \mathrm{c})$ & $8 i$ & 81 & 58 \\
\hline 10 & $p-\mathrm{Br}-\mathrm{Ph}(\mathbf{2 e})$ & $p-\mathrm{BrC}_{6} \mathrm{H}_{4}(2 \mathrm{e})$ & $8 \mathbf{j}$ & 86 & 75 \\
\hline 11 & $p-\mathrm{MeO}-\mathrm{Ph}(\mathbf{2 f})$ & $p-\mathrm{MeOC}_{6} \mathrm{H}_{4}(\mathbf{2 f})$ & $8 k$ & 89 & 73 \\
\hline
\end{tabular}

aproducts were characterized by IR, ${ }^{1} \mathrm{H} N M R,{ }^{13} \mathrm{C}$ NMR and mass spectrometry

bIsolated yields of products after column chromatography

'Yield from mechanochemical synthesis

${ }^{d}$ Yield from conventional heating under neat conditions at $80^{\circ} \mathrm{C}$ for $1 \mathrm{~h}$

\section{Evaluation of anticonvulsant potency}

In pursuance of our on-going projects on bioactive carbo-/heterocycles, an attempt was made to evaluate the anticonvulsant properties of the compounds against Maximal ElectroShock (MES) induced seizure through in vivo rodent models. ${ }^{50}$ Results of the anticonvulsant activity with reference drug phenytoin are provided in Table 1 of ESIt. It was found that all compounds were active at a dose level of $15 \mathrm{mg} / \mathrm{kg}$, which is indicative of their ability to prevent convulsion spread. The MES-convulsions are divided into three phases such as (a) tonic flexion, (b) tonic extensor and (c) clonic convulsions. The time (s) spent by the animal in each phase of the convulsions was noted. A substance is shown to possess anticonvulsant property if it reduces or abolishes the extensor phase of MES-convulsion. Analysis of Table 1 revealed that eleven compounds from the octahydroquinazoline series (8a-k) showed anticonvulsant activity with extensor values lower than that of the standard. 1,3-Unsymmetrically substituted tetrahydropyrimidines (5a-e) emerged as the second most active series with extensor values slightly less than the standard. However, 1,3-symmetrically substituted pyrimidines (3a-g) showed poor activity among the screened series. We rationalized that the symmetric nature of the amine residues in $\mathbf{3 a - g}$ might be the reason for the much reduced activity compared to their unsymmetric counterparts 5a-e. Interestingly, compounds $\mathbf{3 h}$ and $\mathbf{3 i}$ possessing Me and Ph groups respectively at the C-6 position enhanced the anticonvulsant potency, exhibiting extensor time closer to that of phenytoin. This result 
also suggested that a lipophilic alkyl or aryl substitution at C-6 instead of a polar COOR group enhances the activity. Attempts to understand the SAR of the molecules began with the peripheral ring of the molecules. Generally, tetrahydropyrimidine fused to a cyclohexenone ring, the so called 5-oxo-octahydroquinazolines 8a$\mathbf{k}$ increased the potency greatly compared to unfused tetahydropyrimidines 3a-i and 5a-c, suggesting the necessity of a less polar cyclohexyl ring compared to more polar COOR group. Among the most active series, compounds with hydrophobic groups such as $p-\mathrm{MeOC}_{6} \mathrm{H}_{4}$ and $t-\mathrm{Bu}(\mathbf{8 c}$ and $\mathbf{8 i})$ emerged as the most active over all the other compounds. Replacement of $p-\mathrm{MeOC}_{6} \mathrm{H}_{4} 8 \mathrm{c}$ or $t$ - $\mathrm{Bu} 8 \mathbf{8}$ by other hydrophobic groups such as $0, p-$ $\mathrm{Me}_{2} \mathbf{8 d}$ or Bn groups showed only a tiny decrease in activity.

\section{Conclusions}

In summary, we have developed an efficient and practical Au(III)-catalyzed multicomponent reaction for the synthesis of tetrahydropyrimidines and octahydroquinazolines by a mechanochemical approach. Low catalytic loading, short reaction time, good to excellent chemical yields and no solvent used are the beneficial advantages of our methodology. Also, this method is a clean and safe process, and can be used to generate a wide array of structurally interesting hybrid heterocycles. Synthetic elaboration of our methodology to the preparation of clinical drugs as well as molecular docking studies of the most active compounds is actively underway in our laboratory.

\section{Experimental Section}

General. All commercially available solvents and reagents were used without further purification. Melting points were determined in capillary tubes and are uncorrected. Mechanochemical reactions were accomplished in a Fritsch "Pulverisette 7 classic line" (Fritsch $\mathrm{GmbH}$, Idar-Oberstein, Germany) planetary ball mill using $45 \mathrm{~mL}$ grinding beakers (agate) and milling balls (6 X $15 \mathrm{~mm}$; agate). All reaction vessels were cleaned with aqua regia prior to use to avoid any contamination or memory effects. Infrared (IR) spectra were recorded on a Perkin-Elmer FTIR spectrophotometer as neat samples. ${ }^{1} \mathrm{H}$ and ${ }^{13} \mathrm{C}$ NMR spectra were obtained in $\mathrm{CDCl}_{3}$ on a Bruker spectrometer at 500 and $125 \mathrm{MHz}$, respectively. Proton chemical shifts $(\delta)$ are relative to tetramethylsilane (TMS, $\delta=0.00$ ) as internal standard and expressed in parts per million. Spin multiplicities are given as s (singlet), $d$ (doublet), $t$ (triplet) and $m$ (multiplet). Coupling constants $(J)$ are given in Hertz. Mass spectra were recorded on a PE-SCIEX API 300 mass spectrometer. HRMS data were collected on a Maxis 10138 mass spectrometer. Elemental analyses were recorded using a ThermoFinnigan FLASH EA 1112CHN analyzer. All the compounds gave $\mathrm{C}, \mathrm{H}$ and $\mathrm{N}$ analyses within $\pm 0.5 \%$ of the theoretical values. Analytical TLC was performed on precoated plastic sheets of silica gel G/UV-254 of $0.2 \mathrm{~mm}$ thickness (Macherey-Nagel, Germany) using analytical grade solvents and visualized with iodine spray $\left(10 \%(w / w) I_{2}\right.$ in silica gel) or UV light $(\lambda=254$ and $365 \mathrm{~nm}$ ).

Representative experimental procedure for the synthesis of tetrahydropyrimidines (3b). The grinding beakers ( $45 \mathrm{~mL}$; agate) were equipped with 6 milling balls of the same material $(\mathrm{d}=15 \mathrm{~mm})$. Diethyl but-2ynedioate 1a $(1.0 \mathrm{mmoL})$, benzylamine $2 \mathrm{~b}(2.0 \mathrm{mmoL}), \mathrm{NaAuCl}_{4} \cdot 2 \mathrm{H}_{2} \mathrm{O}(1.0 \mathrm{~mol} \%)$ and formaldehyde $(2.0$ $\mathrm{mmoL}$ ) were added in the given order. Ball-milling was carried out at $400 \mathrm{rpm}$ for $5 \mathrm{~min}$. The residue was dissolved in EtOAc $(20 \mathrm{~mL})$ and the extracts washed with $\mathrm{H}_{2} \mathrm{O}(3 \times 15 \mathrm{~mL})$. The organic layer was dried over 
anhydrous $\mathrm{Na}_{2} \mathrm{SO}_{4}$ and the solvent removed under reduced pressure to afford the crude product, which was purified by flash column chromatography using EtOAc/PE (10:90) as eluent to obtain tetrahydropyrimidine $\mathbf{3 b}$ as a viscous yellow liquid in $95 \%$ yield. IR (neat) $v_{\text {max }}$ : 3350, 2979, 1731, 1684, 1585, 1448, 1366, 1279, 1261, 1111, 1036, 1042, $745 \mathrm{~cm}^{-1} ;{ }^{1} \mathrm{H}$ NMR $\left(500 \mathrm{MHz}_{\mathrm{CDCl}}\right): \delta 1.22(\mathrm{t}, 3 \mathrm{H}, J 7.6 \mathrm{~Hz}), 1.30(\mathrm{t}, 3 \mathrm{H}, J 6.8 \mathrm{~Hz}), 3.57(\mathrm{~s}$, $2 \mathrm{H}), 3.61(\mathrm{~s}, 2 \mathrm{H}), 3.83(\mathrm{~s}, 2 \mathrm{H}), 4.12\left(\mathrm{q}, 2 \mathrm{H}, J 6.8 \mathrm{~Hz}\right.$ ) , $4.17(\mathrm{~s}, 2 \mathrm{H}), 4.35(\mathrm{q}, 2 \mathrm{H}, J 7.6 \mathrm{~Hz}), 7.16-7.31(\mathrm{~m}, 10 \mathrm{H}) ;{ }^{13} \mathrm{C}$ NMR $\left(125 \mathrm{MHz}_{\mathrm{CDCl}}\right): \delta$ 13.9, 14.5, 48.6, 54.1, 57.1, 59.7, 62.1, 66.1, 92.5, 127.3, 128.0, 128.1, 128.3, 128.4, 128.7, 136.4, 138.1, 148.2, 165.2, 166.4.; MS: $m / z=409(\mathrm{M}+\mathrm{H})^{+}$. Anal. Calcd for $\mathrm{C}_{24} \mathrm{H}_{28} \mathrm{~N}_{2} \mathrm{O}_{4}: \mathrm{C}, 70.57 ; \mathrm{H}, 6.91$; $\mathrm{N}, 6.86 \%$. Found: $\mathrm{C}, 70.62 ; \mathrm{H}, 6.95 ; \mathrm{N}, 6.78 \%$.

Representative experimental procedure for the synthesis of 5-oxo-octahydroquinazoline (8c). The grinding beakers ( $45 \mathrm{~mL}$; agate) were equipped with 6 milling balls of the same material $(\mathrm{d}=15 \mathrm{~mm})$. A mixture of dimedone $6(1.0 \mathrm{mmoL})$, aniline $2 \mathrm{a}(1.0 \mathrm{mmoL})$ and $\mathrm{NaAuCl}_{4} \cdot 2 \mathrm{H}_{2} \mathrm{O}(1.0 \mathrm{~mol} \%)$ was ball-milled for $30 \mathrm{~min}$ at 400 rpm. Then to this mixture was added $p$-anisidine $2 \mathrm{f}(1.0 \mathrm{mmoL})$, formaldehyde $(2.0 \mathrm{mmoL})$ and the mixture ball-milled for a further $30 \mathrm{~min}$ at $400 \mathrm{rpm}$. Afterwards, the residue was dissolved in EtOAc $(20 \mathrm{~mL})$ and the solution washed with $\mathrm{H}_{2} \mathrm{O}(3 \times 15 \mathrm{~mL})$. The organic layer was dried over anhydrous $\mathrm{Na}_{2} \mathrm{SO}_{4}$ and the solvent was removed under reduced pressure to give crude product, which was purified by flash column chromatography using EtOAc/PE (20:80) as eluent to obtain 5-oxo-octahydroquinazoline 8c as a yellow viscous oil; IR (neat) $V_{\max }: 3454,3049,2949,1568,1505,1399,1289,1252,1036,829,701 \mathrm{~cm}^{-1} ;{ }^{1} \mathrm{H}$ NMR $\left(500 \mathrm{MHz}, \mathrm{CDCl}_{3}\right): \delta 0.92$ $(6 \mathrm{H}, \mathrm{s}), 1.98(2 \mathrm{H}, \mathrm{s}), 2.21(2 \mathrm{H}, \mathrm{s}), 3.74(3 \mathrm{H}, \mathrm{s}), 4.23(2 \mathrm{H}, \mathrm{s}), 4.84(2 \mathrm{H}, \mathrm{s}), 6.78(2 \mathrm{H}, \mathrm{d}, J 9.2 \mathrm{~Hz}), 6.92(4 \mathrm{H}, \mathrm{t}, J 6.1$ $\mathrm{Hz}), 7.27(1 \mathrm{H}, \mathrm{t}, J 7.7 \mathrm{~Hz}), 7.34(2 \mathrm{H}, \mathrm{t}, J 7.7 \mathrm{~Hz}) ;{ }^{13} \mathrm{C} \mathrm{NMR}\left(125 \mathrm{MHz}, \mathrm{CDCl}_{3}\right): \delta 28.4,32.7,41.1,46.0,50.1,55.5$, 71.4, 104.5, 114.5, 119.7, 127.4, 127.5, 129.7, 142.3, 142.8, 154.3, 157.5, 194.2; MS $\mathrm{m} / z=363(\mathrm{M}+\mathrm{H})^{+} ; \mathrm{Anal}$. Calcd for $\mathrm{C}_{23} \mathrm{H}_{26} \mathrm{~N}_{2} \mathrm{O}_{2}$ : C, 76.21; $\mathrm{H}, 7.23$; N 7.73\%; Found: C, 76.14; $\mathrm{H}, 7.28 ; \mathrm{N}, 7.80 \%$.

\section{Acknowledgements}

The work has been financially supported by the fast track grant for young scientists from the Science and Engineering Research Board (SERB), India, which is greatly acknowledged by authors K. K. and C. P. for grants SB/FT/CS-033/2013 and SERB/F/5666/2015-16 respectively.

\section{Supplementary Material}

Supplementary data contains complete characterization data, NMR spectra of representative compounds and anticonvulsant results of all compounds.

\section{References}

1. Tanaka, K.; Toda, F. Chem. Rev. 2000, 100, 1025. https://doi.org/10.1021/cr940089p

2. Tietze, L. F. Chem. Rev. 1996, 96, 115. https://doi.org/10.1021/cr950027e

3. Martins, M. A. P.; Frizzo, C. P.; Moreira, D. N.; Buriol, L.; Machado, P. Chem. Rev. 2009, 109, 4140. https://doi.org/10.1021/cr9001098 
4. Chanda, A.; Fokin, V. V. Chem. Rev. 2009, 109, 725.

https://doi.org/10.1021/cr800448q

5. Siamaki, A. R.; Arndtsen, B. A. J. Am. Chem. Soc. 2006, 128, 6050. https://doi.org/10.1021/ja060705m

6. Looper, R. E.; Runnegar, M. T. C.; Williams, R. M. Angew. Chem. Int. Ed. 2005, 44, 3879. https://doi.org/10.1002/anie.200500520

7. Kobayashi, J.; Kanda, F.; Ishibashi, M.; Shigemori, H. J. Org. Chem. 1991, 56, 4574. https://doi.org/10.1021/jo00014a052

8. Skinner, G. S.; Wunz, P. R. J. Am. Chem. Soc. 1951, 73, 3814. https://doi.org/10.1021/ja01152a074

9. Malin, G.; lakobashvili, R.; Lapidot, A. J. Biol. Chem. 1999, 274, 6920. https://doi.org/10.1074/jbc.274.11.6920

10. Pattarini, R.; Smeyne, R. J.; Morgan, J. I. Neuroscience 2007, 145, 654. https://doi.org/10.1016/j.neuroscience.2006.12.030

11. Nair, A. C.; Jayatilleke, P.; Wang, X.; Miertus, S.; Welsh, W. J. J. Med. Chem. 2002, 45, 973. https://doi.org/10.1021/jm010417v

12. Brough, P.; Pecaut, J.; Rassat, A.; Rey. P. Chem. Eur. J. 2006, 12, 5134. https://doi.org/10.1002/chem.200600061

13. Kang, S. H.; Kang, S. Y.; Lee, H. S.; Buglass, A. J. Chem. Rev. 2005, 105, 4537. https://doi.org/10.1021/cr040608g

14. Darandale, S. N.; Pansare, D. N.; Mulla, N. A.; Shinde, D. B. Bioorg. Med. Chem. Lett. 2013, $23,2632$. https://doi.org/10.1016/j.bmcl.2013.02.099

15. Zhang, M.; Jiang, H.; Liu, H.; Zhu, Q. Org. Lett. 2007, 9, 4111. https://doi.org/10.1021/ol701592

16. Lingaiah, N.; Reddy, V. H.; Venkatanarasimhaji, Ch.; Rajashekar, B.; Reddy, A. R. Synth. Commun. 2012, 42, 2131.

https://doi.org/10.1080/00397911.2011.554061

17. Vadivelu, M.; Sugirdha, S.; Dheenkumar, P.; Arun, Y.; Karthikeyan, K.; Praveen, C. Green Chem. 2017, 19, 3601.

https://doi.org/10.1039/C7GC01284E

18. Parthasarathy, K.; Praveen, C.; Saranraj, K.; Balachandran, C.; Kumar, P. S. Med. Chem. Res. 2016, 25, 2155.

https://doi.org/10.1007/s00044-016-1645-4

19. Parthasarathy, K.; Praveen, C.; Balachandran, B.; Kumar, P. S.; Perumal, P. T. RSC Adv. 2015, 5, 15818. https://doi.org/10.1039/C4RA16605A

20. Praveen, C.; Parthasarathy, K.; Kumar, P. S.; Perumal, P. T. Ind. J. Chem. Sect (B) 2015, 54B, 373.

21. Parthasarathy, K.; Praveen, C.; Balachandran, B.; Kumar, P. S.; Ignacimuthu, S.; Perumal, P. T. Bioorg. Med. Chem. Lett. 2013, 23, 2708.

https://doi.org/10.1016/j.bmcl.2013.02.086

22. Praveen, C.; Narendiran, S.; Dheenkumar, P.; Perumal, P. T. J. Chem. Sci. 2013, 125, 1543. https://doi.org/10.1007/s12039-013-0510-y

23. Praveen, C.; Dheenkumar, P.; Perumal, P. T. J. Chem. Sci. 2013, 125, 71. https://doi.org/10.1007/s12039-012-0325-2 
24. Praveen, C.; Iyyappan, C.; Girija, K.; Kumar, K. S.; Perumal, P. T. J. Chem. Sci. 2012, 124, 451. https://doi.org/10.1007/s12039-011-0150-z

25. Praveen, C.; Iyyappan, C.; Perumal, P. T.; Girija, K. Ind. J. Chem. Sec (B) 2012, 51B, 498.

26. Praveen, C.; Nandakumar, A.; Dheenkumar, P.; Muralidharan, D.; Perumal, P. T. J. Chem. Sci. 2012, 124, 609.

https://doi.org/10.1007/s12039-012-0251-3

27. Praveen, C.; Ayyanar, A.; Perumal, P. T. Bioorg. Med. Chem. Lett. 2011, 21, 4072. https://doi.org/10.1016/j.bmcl.2011.04.117

28. Praveen, C.; Parthasarathy, K. Perumal, P. T. Synlett 2010, 1635.

29. Praveen, C.; Iyyappan, C.; Perumal, P. T. Tetrahedron Lett. 2010, 51, 4767. https://doi.org/10.1016/i.tetlet.2010.07.030

30. Praveen, C.; DheenKumar, P.; Muralidharan, D.; Perumal, P. T. Bioorg. Med. Chem. Lett. 2010, $20,7292$. https://doi.org/10.1016/j.bmcl.2010.10.075

31. Iyyappan, C.; Praveen, C.; Hemalatha, K.; Girija, K. Int. J. Pharm. Bio. Sci. 2010, 1, 323.

32. Praveen, C.; Kumar, K. H.; Muralidharan, D.; Perumal, P. T. Tetrahedron 2008, 64, 2369. https://doi.org/10.1016/j.tet.2008.01.004

33. Praveen, C.; Ananth, D. B. Bioorg. Med. Chem. Lett. 2016, 26, 2507. https://doi.org/10.1016/j.bmcl.2016.03.087

34. Parthasarathy, K.; Praveen, C.; Jeyaveeran, J. C.; Prince, A. A. M. Bioorg. Med. Chem. Lett. 2016, $26,4310$. https://doi.org/10.1016/i.bmcl.2016.07.036

35. Praveen, C.; Perumal, P. T. Chin. J. Catal. 2016, 37, 288. https://doi.org/10.1016/S1872-2067(15)60994-9

36. Jeyaveeran, J. C.; Praveen, C.; Arun, Y.; Prince, A. A. M.; Perumal, P. T. J. Chem. Sci. 2016, $128,787$. https://doi.org/10.1007/s12039-016-1070-8

37. Jeyaveeran, J. C.; Praveen, C.; Arun, Y.; Prince, A. A. M.; Perumal, P. T. J. Chem. Sci. 2016, $128,73$. https://doi.org/10.1007/s12039-015-0993-9

38. Praveen, C.; Perumal, P. T. Synthesis, 2016, 48, 855. https://doi.org/10.1055/s-0035-1561305

39. Parthasarathy, K.; Ponpandian, T.; Praveen, C. Chin. J. Catal. 2017, 38, 755. https://doi.org/10.1016/S1872-2067(17)62812-2

40. Praveen, C.; Ayyanar, A.; Perumal, P. T. Bioorg. Med. Chem. Lett. 2011, 21, 4170. https://doi.org/10.1016/j.bmcl.2011.05.088

41. Praveen, C.; Perumal, P. T. Synlett 2011, 521.

42. Balakrishnan, B.; Praveen, C.; Seshadri, P. R.; Perumal, P. T. Acta. Cryst. 2011, E67, 01575.

43. Praveen, C.; Kalyanasundaram, A.; Perumal, P. T. Synlett 2010, 777.

44. Praveen, C.; Jegatheesan, S.; Perumal, P. T. Synlett 2009, 2795.

45. Praveen, C.; Kiruthiga, P.; Perumal, P. T. Synlett 2009, 1990.

46. Praveen, C.; karthikeyan, K.; Perumal, P. T. Tetrahedron 2009, 65, 9244. https://doi.org/10.1016/j.tet.2009.09.019

47. Praveen, C.; Sagayaraj, Y. W.; Perumal, P. T. Tetrahedron Lett. 2009, 50, 644. https://doi.org/10.1016/j.tetlet.2008.11.086

48. Balakrishnan, B.; Praveen, C.; Seshadri, P. R.; Perumal, P. T. Acta. Cryst. 2013, E69, o597. 
49. James, S. L.; Adams, C. J.; Bolm, C.; Braga, D.; Collier, P.; Friščić, T.; Grepioni, F.; Harris, K. D. M.; Hyett, G.; Jones, W.; Krebs, A.; Mack, J.; Maini, L.; Orpen, A. G.; Parkin, I. P.; Shearouse, W. C.; Steed, J. W.; Wadell, D. C. Chem. Soc. Rev. 2012, 41, 413. https://doi.org/10.1039/C1CS15171A

50. Yogeeswari, P.; Sriram, D.; Thirumurugan, R.; Raghvendran, J.; Sudan, K.; Pavana, R.; Stables, J. J. Med. Chem. 2005, 48, 6202.

https://doi.org/10.1021/jm050283b 